Brit. Heart f., 1967, 29, 742.

\title{
Cardiac Arrhythmias Following Successful Surgical Closure of Atrial Septal Defect
}

\author{
J. M. REID AND J. C. STEVENSON \\ From The Cardio-Thoracic Unit, Mearnskirk Hospital, Newton Mearns, Renfrewshire
}

Atrial septal defect is a common congenital cardiac malformation, but is one which is readily amenable to surgical correction using either hypothermia (Swan et al., 1959; Morrow et al., 1960; Julian et al., 1962; Zellos, 1964) or cardiopulmonary bypass (Husfeldt and Davidsen, 1961; American College of Chest Physicians, 1963) as a supportive technique. The mortality from the operation is low (American College of Chest Physicians, 1963; Zellos, 1964) and the long-term results are strikingly good (Swan et al., 1959). Childhood is manifestly the best time for operation, as both pulmonary hypertension and right ventricular hypertrophy are uncommon then. In adults both are more frequently encountered, and mortality and morbidity are appreciably higher. Furthermore, one would expect cardiac arrhythmias to be more common in this age-group. Where additional lesions are present or the defect is of the primum type, there is greater disturbance of hæmodynamics, and again one would reasonably anticipate a higher incidence of complications and arrhythmias.

The object of this communication is to review 151 patients with atrial septal defect occurring either alone or with accompanying lesions. An attempt has been made to ascertain the number who had cardiac arrhythmias before operation or who developed these afterwards, and these observations have been correlated with the patients' age, presence or otherwise of pulmonary arterial hypertension, type of defect, and certain other factors.

\section{MATERIAL}

The period under review covers the years 1956 to October 1966, during which time 151 patients with atrial septal defect were operated on. Table I indicates the type of defect present and the presence or otherwise of accompanying congenital cardiac malformations. As

Received January 17, 1967. in most other series (American College of Chest Physicians, 1963), the secundum type of atrial septal defect occurring as a solitary anomaly was by far the commonest, the ostium primum variety in our experience being comparatively rare. The age range of the patients was from 3 to 44 years, but the overwhelming majority were aged 3-15 years (Table II). The ratio of female to male patients was $94: 57$.

TABLE I

TYPE OF DEFECT IN 151 PATIENTS

\begin{tabular}{c|c|c|c|c|c}
\hline $\begin{array}{c}\text { Uncompli- } \\
\text { cated } \\
\text { secundum } \\
\text { ASD }\end{array}$ & $\begin{array}{c}\text { Secundum } \\
\text { ASD + } \\
\text { anom. pul. } \\
\text { ven. } \\
\text { drainage }\end{array}$ & $\begin{array}{c}\text { Secundum } \\
\text { ASD + } \\
\text { pulm. } \\
\text { stenosis }\end{array}$ & $\begin{array}{c}\text { Primum } \\
\text { ASD }\end{array}$ & $\begin{array}{c}\text { Sinus } \\
\text { venosus }\end{array}$ & $\begin{array}{c}\text { Secundum } \\
\text { ASD + } \\
\text { VSD }\end{array}$ \\
\hline 116 & 14 & 10 & 5 & 3 & 3 \\
\hline
\end{tabular}

TABLE II

AGE-GROUPS OF 151 PATIENTS WITH ASD

\begin{tabular}{c|c|c|c|c}
\hline $0-10$ & $11-20$ & $21-30$ & $31-40$ & $41-50$ \\
\hline 93 & 25 & 22 & 7 & 4 \\
\hline
\end{tabular}

\section{SURGical TeChNique}

In only one patient ( the first of the series) was repair of the defect carried out blindly, using the Söndergaard technique. Open repair was effected in the remainder using either moderate hypothermia $\left(31-32^{\circ} \mathrm{C}\right.$.) with inflow occlusion or cardiopulmonary bypass. In our experience, hypothermia readily permits the closure of all secundum defects by direct suture, and is for us the method of choice. Of the 116 patients with secundum defects, 92 were operated on under hypothermia. Cardiopulmonary bypass was reserved for cases with accompanying malformations (pulmonary stenosis or ventricular septal defect), or where the defect was considered to 742 
partial pulmonary venous drainage. Oscilloscope cardiogram monitoring was observed in all patients during operation and for the first 24 hours thereafter. Any arrhythmia occurring during this period was readily noted, recorded, and then serially observed by conventional recordings. In the great majority, sinus rhythm prevailed in the first 24 hours. These patients required only routine pulse observations followed later in the post-operative period by a pre-discharge cardiogram.

\section{CARDIAC ARRHYThMIAS}

Omitting transient cardiac irregularity during the course of operation, there were 13 instances of postoperative arrhythmia. This represents an over-all incidence of 9 per cent in the 151 patients. The various types of arrhythmia are given in Table III.

TABLE III

TYPES OF ARRHYTHMIA IN 13 PATIENTS

\begin{tabular}{c|c|c|c|c}
\hline $\begin{array}{c}\text { Atrial } \\
\text { flutter }\end{array}$ & $\begin{array}{c}\text { Atrial } \\
\text { fibrillation }\end{array}$ & $\begin{array}{c}\text { Heart } \\
\text { block }\end{array}$ & $\begin{array}{c}\text { Supra- } \\
\text { ventricular } \\
\text { tachycardia }\end{array}$ & $\begin{array}{c}\text { Nodal } \\
\text { rhythm }\end{array}$ \\
\hline 5 & 4 & 2 & 1 & 1 \\
\hline
\end{tabular}

Of the 13, 10 had secundum defects (an incidence of $8.5 \%$ in the 116 patients with such defects). Of the remainder, one had a secundum defect complicated by anomalous drainage of the inferior vena cava and has been previously reported elsewhere (Reid, McGuiness, and Welsh, 1965), another had
Lutembacher's syndrome, and the thirteenth had a primum defect with mitral stenosis accompanied by severe pulmonary arterial hypertension. Of the 13 patients under discussion, 6 were aged 3-14 years, the age range of the other 7 being 22-42 years. Severe pulmonary artery hypertension (a systolic pressure greater than $70 \mathrm{~mm} . \mathrm{Hg}$ ) was recorded in 2 , and in 3 it was moderate (less than $70 \mathrm{~mm} . \mathrm{Hg}$ ). Hypothermia was used in 5 and bypass in 8 patients.

Treatment of Arrhythmias. The patient who developed nodal rhythm was a child aged 4 years with a large secundum defect and severe pulmonary hypertension. Nodal rhythm was noted on the day following repair of the lesion while the child was on controlled ventilation. Atrial flutter with 3:1 block supervened 24 hours later (Fig. 1). Death occurred on the third day, and necropsy disclosed that the defect was soundly closed; the mitral valve, however, was grossly deformed.

Digoxin was administered to the 5 patients who developed atrial flutter, the one with supraventricular tachycardia, and the 4 with atrial fibrillation. Sinus rhythm was restored in all but 3 of these. Cardioversion (using the Lown cardioverter, with 1 shock of 50 watt/sec. under a short general anæsthetic) was successful in re-establishing normal rhythm in the 3 patients who did not respond to drug therapy. Following electrical conversion, quinidine was given for six weeks, sinus rhythm being satisfactorily maintained after treatment was stopped (Fig. 2, 3, and 4).

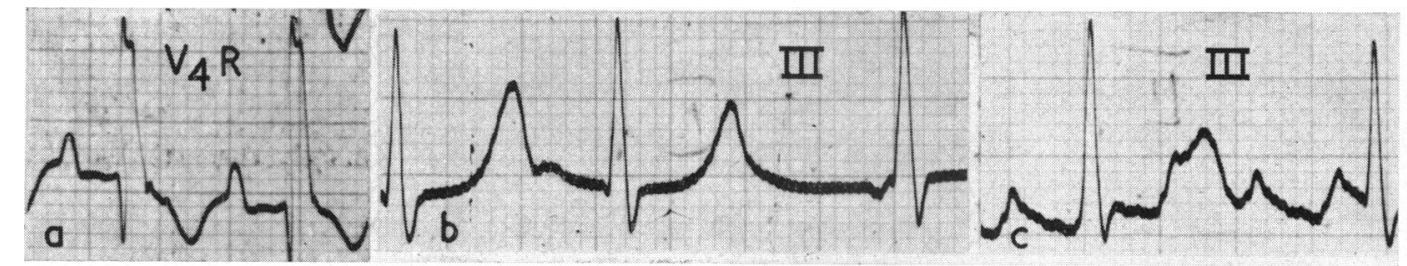

FIG. 1.-Girl aged 4 years with Lutembacher's syndrome and severe pulmonary hypertension. (a) Preoperative cardiogram, with tall $R$ wave. (b) Two hours after operation, with wandering pacemaker (varying nodal rhythm). (c) 20 hours after operation; rhythm has altered to atrial flutter with $3: 1$ block.

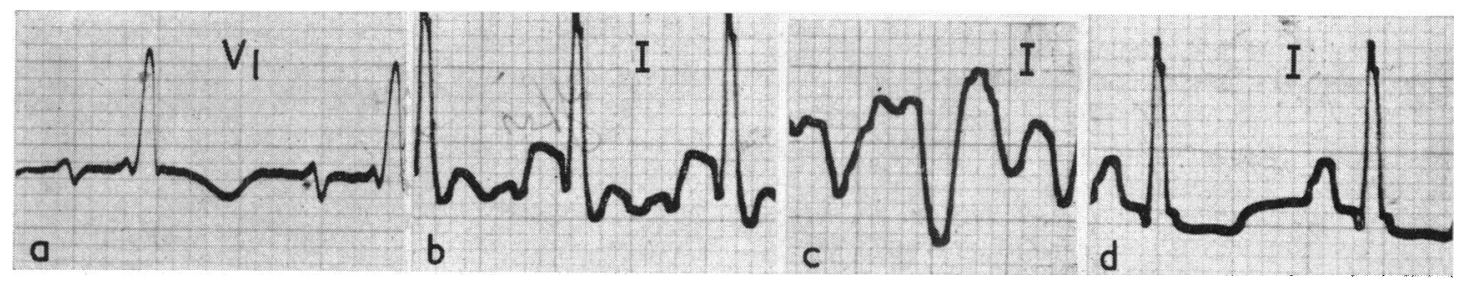

FIG. 2.-Woman aged 22 years with secundum ASD. (a) Pre-operative electrocardiogram. (b) Persistent atrial flutter after operation, with $2: 1$ block. (c) Short period of ventricular fibrillation during cardioversion. (d) Sinus rhythm successfully restored after second electrical shock. 


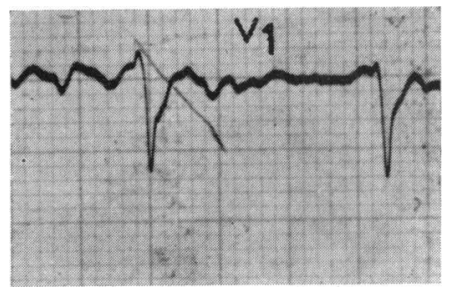

FIG. 3.-Man aged 27 years with secundum ASD. Postoperative atrial fibrillation before cardioversion.

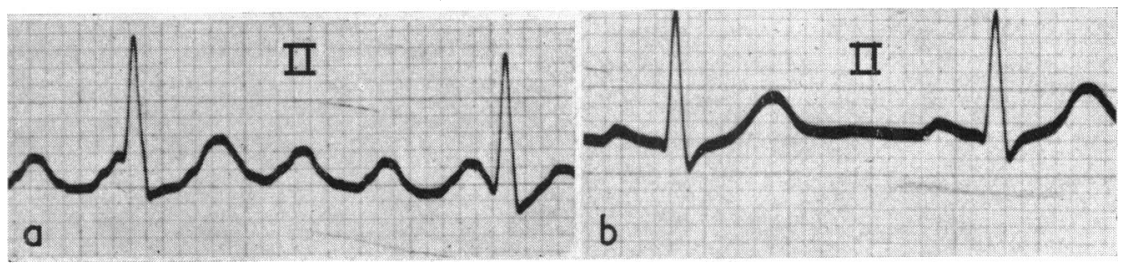

FIG. 4.-Girl aged 14 years with secundum ASD. (a) Post-operative atrial flutter with $3: 1$ block. (b) Sinus rhythm restored following cardioversion.

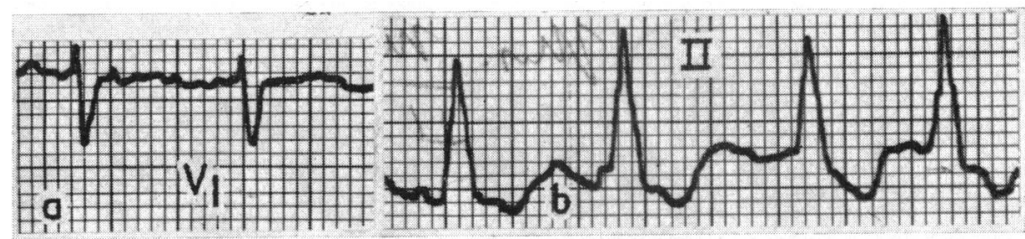

Fig. 5.-Woman aged 40 years with large secundum ASD. (a) Atrial fibrillation two hours after operation. (b) 3 hours after operation, there is gross irregularity with ectopic ventricular beats, preceding ventricular fibrillation and death.

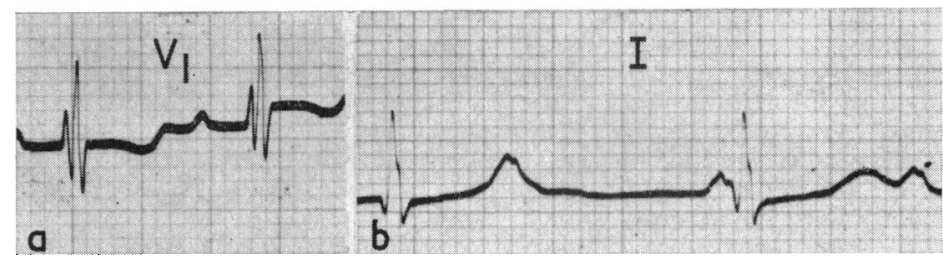

FIG. 6.-Girl aged 4 years with ostium primum and severe pulmonary hypertension. (a) Pre-operative electrocardiogram, with $q R$ (see text); $R=12 \mathrm{~mm}$. (b) After repair of defect, there is complete heart block with ventricular rate of 60 a minute.

In one patient aged 40 years atrial fibrillation was replaced by ectopic ventricular beats followed by ventricular fibrillation and death (Fig. 5).

The two patients in whom heart block was encountered warrant more detailed comment. The first was a child aged 4 years with a primum defect, marked pulmonary arterial hypertension, and mitral stenosis. Operation was carried out with cardiopulmonary bypass, and following repair of the defect by means of a pericardial patch, mitral valvotomy was performed. Complete heart block was noted at the end of operation, the ventricular rate being 60 a minute (Fig. 6). The child rapidly lapsed into cardiac failure with severe pulmonary congestion. Intensive diuretic therapy slowly controlled the failure, but complete atrio-ventricular dissociation persisted. Gradually the over-all condition improved, and the child was eventually discharged from hospital reasonably well but with complete heart block. The implantation of an artificial pacemaker or the oral administration of a long-acting isoprenaline preparation had both been entertained, 


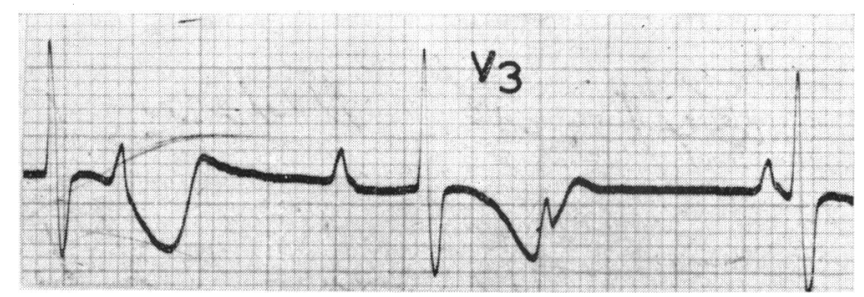

FIG. 7.-Boy aged 6 years with secundum ASD. Pre-operative electrocardiogram, showing congenital heart block $(2: 1)$ and marked $T$ inversion.

but dismissed, perhaps, in retrospect, too precipitately. We have since heard of the child's demise in another region eight months after operation, and we cannot dissociate her death from her persistent heart block.

The second patient with heart block was a boy aged 6 years with a secundum defect, in whom congenital $2: 1$ block was present before operation (Fig. 7). Operation passed without incident, and he made a completely smooth recovery, the degree of conduction defect being unaltered. This congenital variety of heart block is recognized as having a good prognosis (Nadas, 1963). It adds little to the hæmodynamic burden of a heart adapted from infancy.

\section{Discussion}

It is noteworthy that in the 13 patients who developed cardiac arrhythmias after operation, 10 had secundum defects and only 3 had more complex malformations (primum defect or Lutembacher's syndrome). However, of the 10 with secundum defects, 7 were aged 22 years or over, and one had heart block before operation.

Zellos (1964), reporting a series of 133 cases of secundum defects closed under hypothermia, found atrial fibrillation transiently in more than half, but in three it persisted for six months. An additional two had sinus tachycardia for a similar period. However, 56 of his cases were aged 21 years or over, compared with 33 in the series under discussion, and it may well be that the higher incidence of arrhythmia after operation in Zellos' patients is related to a greater proportion of older patients. Pulmonary hypertension is comparatively rare in secundum defects in children, but is encountered more frequently with increasing age. Thus, age and pulmonary hypertension appear to be important factors in precipitating arrhythmia in the immediate post-operative period.

Watkins and Gross (1955) reviewed 46 patients who underwent closure of an atrial septal defect when this branch of cardiac surgery was in its developmental phase. The atrial well technique was employed. Their patients, in the main, had more serious cardiac disability than is usual in presentday surgery where absence of symptoms is almost the rule in uncomplicated cases. Their criteria for operation were incapacitating symptoms, serious cardiac enlargement, and pulmonary congestion. Not surprisingly, arrhythmias were frequently encountered 3 to 14 days after operation, and were accompanied in many instances by congestive cardiac failure. Atrial fibrillation was the commonest disturbance noted, but the arrhythmias tended to subside with control of the cardiac failure by means of digitalis and diuretics.

In a very large survey carried out by the American College of Chest Physicians (1963) on 2401 patients with atrial septal defect treated surgically at several centres, the Committee who reported on the findings concluded that the mortality and incidence of conduction defects were similar when either bypass or hypothermia was used. In secundum defects, the percentage of conduction defects was 4-5 per cent, but was very substantially higher with the more complex primum type $(26 \%)$. We had no conduction defect following closure of a seundum defect, but complete heart block ensued after operation in one of our five primum malformations. We would dispute the contention of the American College of Chest Physicians that bypass is the method of choice for closure of all types of atrial septal defects, as we consider that solitary secundum defects are eminently amenable to repair in the time afforded by moderate hypothermia.

Davies, Pryor, and Blount (1960) made a careful electrocardiographic study of the QRS complex in the præcordial leads in patients with atrial septal defect. They described four types of abnormality which mirrored increasing strain and hypertrophy of the right ventricle. The $\mathrm{rR}^{1}$ and $\mathrm{qR}$ patterns, the most severe, signified diastolic overload and dilatation of the right ventricle, and correlated well with the level of pulmonary artery pressure. In our 13 patients the cardiographic pattern in 5 was of the rSr pattern (type (a) in this classification), 6 showed an $\mathrm{rSr}^{1}$ in $\mathrm{V}_{1}$, and there was one each of the 
two more severe grades, (c) and (d), or $r R^{1}$ and $q R$, respectively, representing diastolic overloading and dilatation of the right ventricle. There was considerable pulmonary hypertension in these two patients, the respective pressures being $65 / 20$ and $55 / 15 \mathrm{~mm}$. Hg.

Somerville (1960) found that by inducing hypothermia to $30^{\circ} \mathrm{C}$. in patients with various arrhythmias (atrial fibrillation, atrial flutter, and ectopic ventricular beats), in many instances sinus rhythm became apparent as a temporary phenomenon. This may well be due to a prolongation of the refractory period of atrial muscle with abolition of abnormal rhythms. However, Tofler (1962) observed that further reduction of the temperature caused bradycardia, atrial fibrillation, ventricular fibrillation, and finally asystole at $13^{\circ} \mathrm{C}$.

Cooper (1961) stated that in the limitation of arrhythmias, important parameters were the arterial $\mathrm{PCO}_{2}, p \mathrm{H}$, and serum potassium and calcium levels. Unfortunately we have insufficient biochemical data on our patients who developed arrhythmias to comment on this postulate, as most were operated on under hypothermia with minimal biochemical control.

The sino-auricular node, situated in the atrium near the entrance of the superior vena cava, is very susceptible to trauma during cardiac operations (Hudson, 1960). If the greatest care is not exercised, it may be divided by the atrial incision, crushed by forceps, or damaged by sutures. This can occur particularly if the node is small and has depleted muscle, and may well produce post-operative arrhythmias. That such arrhythmias are much more common after repair of primum defects or secundum ones in older patients with pulmonary artery hypertension is understandable in the light of Hudson's painstaking study of the histopathology of the node. In these circumstances the right ventricle and atrium are invariably grossly dilated and hypertrophied, and one can appreciate that even minimal trauma at operation can adversely affect the node.

It appears thus that increasing age, severe right ventricular hypertrophy and strain, and the presence of pulmonary arterial hypertension all act adversely to produce arrhythmias either before or after closure of an atrial septal defect. In childhood, at least, accompanying malformations such as pulmonary stenosis or partial anomalous venous drainage do not produce any additional propensity to arrhythmias, though such is not the case with primum defects. The optimum time for surgical closure, as in most congenital cardiac malformations, is early childhood when the mortality and risks of arrhythmia should be minimal.

\section{SUMMARY}

In a series of 151 surgically treated cases of atrial septal defect, cardiac arrhythmias were encountered in 13 instances. The two commonest irregularities were atrial flutter and atrial fibrillation, but there was one instance each of supraventricular tachycardia, nodal rhythm, and heart block. A further patient had 2:1 heart block before operation but made a smooth recovery. With the exception of atrio-ventricular dissociation, the arrhythmias were not permanent, though cardioversion proved necessary on three occasions.

The principal predisposing factors are increasing age and the presence of pulmonary arterial hypertension, as these lead to progressive hypertrophy and strain on the right heart, which in turn renders the sino-atrial node more susceptible to derangement.

The authors wish to express their thanks to Dr. E. N. Coleman, Department of Cardiology, The Royal Hospital for Sick Children, Glasgow, who was responsible for the investigation of many of the patients included in this paper. They are also indebted to Professor J. H. Hutchison and many other physicians at the Royal Hospital for Sick Children, Glasgow, for referring cases for operation and, in addition, to physicians in other areas in the region. The surgical treatment of all the patients was carried out by Mr. R. S. Barclay, Mr. T. M. Welsh, and Mr. N. McSwan, and the electrocardiographic reproductions were carried out by Mr. Gray, Department of Medical Illustration, The Victoria Infirmary, Glasgow. To all these the authors are indebted.

\section{REFERENCES}

American College of Chest Physicians (1963). Survey of surgical treatment of atrial septal defects. Report of the Committee on Cardiovascular Surgery. Dis. Chest, 43, 447.

Cooper, K. E. (1961). The circulation in hypothermia. Brit. med. Bull., 17, 48.

Davies, D. H., Pryor, R., and Blount, S. G., Jr. (1960). Electrocardiographic changes in atrial septal defect following surgical correction. Brit. Heart f., 22, 274.

Hudson, R. E. B. (1960). The human pacemaker and its pathology. Brit. Heart f., 22, 153.

Husfeldt, E., and Davidsen, H. G. (1961). Atrial septal defect. F. cardiovasc. Surg. (Torino), 2, 20.

Julian, O. C., Dye, W. S., Javid, H., and Hunter, J. A. (1962). Cardiovascular Surgery, pp. 290 and 292. Year Book Medical Publishers, Chicago.

Morrow, A. G., Gilbert, J. W., Baker, R. R., and Collins, N. P. (1960). The closure of atrial septal defects utilizing general hypothermia. f. thorac. cardiovasc. Surg., 40, $6,776$.

Nadas, A. S. (1963). Pediatric Cardiology, 2nd ed., p. 251. W. B. Saunders, Philadelphia and London.

Reid, J. M., McGuiness, J., and Welsh, T. M. (1965). An unusual cause of cyanosis in atrial septal defect of secundum type. Scot. med. F., 10, 384. 
Somerville, W. (1960). The effect of hypothermia on atrial fibrillation and other arrhythmias. Brit. Heart f., 22, 515.

Swan, H., Kortz, A. B., Davies, D. H., and Blount, S. G., Jr. (1959). Atrial septal defect, secundum. An analysis of 100 patients undergoing open surgical repair. $\mathcal{F}$. thorac. Surg., 37, 1, 52.
Tofler, O. B. (1962). Electrocardiographic changes during profound hypothermia. Brit. Heart f., 24, 265.

Watkins, E., Jr., and Gross, R. E. (1955). Experiences with surgical repair of atrial septal defects. F. thorac. Surg., $30,469$.

Zellos, S. (1964). Surgical treatment of atrial septal defect under hypothermia. Thorax, 19, 481. 